\title{
Physical Examination and Ultrasound Evaluation of Patients with Superficial Venous Disease
}

\author{
Leigh C. Casadaban, MD ${ }^{1}$ John M. Moriarty, MD, FSIR, FSVM ${ }^{1}$ Cheryl H. Hoffman, MD, FSIR, RPVI ${ }^{1}$ \\ ${ }^{1}$ Division of Interventional Radiology, Department of Radiological \\ Sciences, David Geffen School of Medicine at UCLA, Los Angeles, \\ California \\ Address for correspondence Cheryl Hoffman, MD, FSIR, RPVI, \\ Division of Interventional Radiology, Department of Radiological \\ Sciences, David Geffen School of Medicine at UCLA, Los Angeles, CA \\ (e-mail: CHHoffman@mednet.ucla.edu). \\ Semin Intervent Radiol 2021;38:167-175
}

Abstract
Keywords
- superficial venous
$\quad$ disease
- physical examination
- duplex
ultrasonography
- interventional
radiology

Systematic and standardized evaluation of superficial venous disease, guided by knowledge of the various clinical presentations, venous anatomy, and pathophysiology of reflux, is essential for appropriate diagnosis and optimal treatment. Duplex ultrasonography is the standard for delineating venous anatomy, detecting anatomic variants, and identifying the origin of venous insufficiency. This article reviews tools and techniques essential for physical examination and ultrasound assessment of patients with superficial venous disease.
Superficial venous disease is often perceived as a cosmetic illness; however, symptoms can be debilitating and often underdiagnosed, misdiagnosed, or mismanaged. ${ }^{1}$ Venous disease has a range of manifestations from asymptomatic telangiectasias to venous edema, fibrosis, and active venous ulcerations. As many as $40 \%$ of Americans suffer from venous reflux, and one-third have advanced venous disease. ${ }^{2}$

Understanding the etiology, pathophysiology, and natural progression of disease is imperative. Superficial venous disease etiology is typically genetic, as there is an abnormality in the vein wall integrity related to quality and volume of collagen and elastic fibers. ${ }^{3}$ These abnormalities contribute to vein enlargement and valvular incompetence, resulting in increased venous hypertension and impaired return of blood. ${ }^{4}$ Additionally, the integrity of the venous muscle pumps is essential. Without ambulation and calf contraction, there is increased venous stasis. Other risk factors include increasing age, obesity, prolonged standing, history of deep vein thrombosis, and number of prior pregnancies. ${ }^{3,5}$ Female gender was once considered to be a risk factor but may actually carry less risk than previously thought. ${ }^{5}$ Newer studies are showing an association with increased height. ${ }^{6}$

Issue Theme Interventional Radiology in Nonthrombotic Venous Interventions; Guest Editors, Ramona Gupta, MD and Ronald S. Winokur, MD

Clinical symptoms, such as leg cramping, heaviness, and edema, are worse later in the day. Symptoms are exacerbated by prolonged standing and relieved with leg elevation. Other clinical symptoms of superficial venous disease include skin changes such as brown discoloration, eczema, and restless leg syndrome. Symptoms and impact on quality of life can be documented with standardized reporting, for which there are various assessment tools. One validated and reproducible scoring system is the venous clinical severity score (VCSS), which was revised (VCSS-R) in 2010 and includes 10 attributes with 4 grades. $^{7}$ A separate score is calculated for each leg (-Table 1). The VCSS-R is a clinical assessment tool that is documented on each patient in the history of present illness. This precedes a complete physical examination and ultrasound evaluation, all of which contribute to a comprehensive evaluation of patients with superficial venous disease.

\section{Physical Exam}

The physical exam is guided by the CEAP (clinical manifestations, etiologic factors, anatomic distribution, and underlying pathophysiology) classification, which is a worldwide

(c) 2021. Thieme. All rights reserved. Thieme Medical Publishers, Inc., 333 Seventh Avenue, 18th Floor, New York, NY 10001, USA
DOI https://doi.org/ 10.1055/s-0041-1727103. ISSN 0739-9529. 
Table 1 Venous clinical severity score, 2010 revision (VCSS-R) worksheet

\begin{tabular}{|c|c|c|c|c|c|c|c|c|}
\hline Attribute & \multicolumn{2}{|c|}{ Absent $=0$} & \multicolumn{2}{|c|}{ Mild $=1$} & \multicolumn{2}{|c|}{ Moderate $=2$} & \multicolumn{2}{|c|}{ Severe $=3$} \\
\hline \multirow[t]{2}{*}{$\begin{array}{l}\text { Pain or other discomfort } \\
\text { (i.e., aching, heaviness, } \\
\text { fatigue, soreness, burning) }\end{array}$} & \multicolumn{2}{|c|}{ None } & \multicolumn{2}{|c|}{$\begin{array}{l}\text { Occasional, } \\
\text { not restricting } \\
\text { daily activities }\end{array}$} & \multicolumn{2}{|c|}{$\begin{array}{l}\text { Interferes but } \\
\text { does not } \\
\text { prevent } \\
\text { regular daily } \\
\text { activities }\end{array}$} & \multicolumn{2}{|c|}{$\begin{array}{l}\text { Limits most } \\
\text { regular daily } \\
\text { activities }\end{array}$} \\
\hline & Rt & $\mathrm{Lt}$ & Rt & $\mathrm{Lt}$ & Rt & $\mathrm{Lt}$ & Rt & $\mathrm{Lt}$ \\
\hline \multirow[t]{2}{*}{$\begin{array}{l}\text { Varicose veins } \\
\geq 3 \mathrm{~mm} \text { diameter in standing position }\end{array}$} & \multicolumn{2}{|c|}{ None } & \multicolumn{2}{|c|}{$\begin{array}{l}\text { Few: } \\
\text { (also corona } \\
\text { phlebectatica) }\end{array}$} & \multicolumn{2}{|c|}{ Calf or thigh } & \multicolumn{2}{|c|}{ Calf and thigh } \\
\hline & Rt & $\mathrm{Lt}$ & Rt & $\mathrm{Lt}$ & Rt & $\mathrm{Lt}$ & Rt & $\overline{\mathrm{Lt}}$ \\
\hline \multirow[t]{2}{*}{ Venous edema } & \multicolumn{2}{|c|}{ None } & \multicolumn{2}{|c|}{ Foot and ankle } & \multicolumn{2}{|c|}{$\begin{array}{l}\text { Above ankle } \\
\text { and below } \\
\text { knee }\end{array}$} & \multicolumn{2}{|c|}{$\begin{array}{l}\text { To knee and } \\
\text { above knee }\end{array}$} \\
\hline & Rt & $\mathrm{Lt}$ & Rt & Lt & Rt & $\mathrm{Lt}$ & Rt & $\overline{\mathrm{Lt}}$ \\
\hline \multirow[t]{2}{*}{ Skin pigmentation } & \multicolumn{2}{|c|}{ None or focal } & \multicolumn{2}{|c|}{ Perimalleolar } & \multicolumn{2}{|c|}{$\begin{array}{l}\text { Lower third of } \\
\text { calf }\end{array}$} & \multicolumn{2}{|c|}{$\begin{array}{l}\text { Above lower } \\
\text { third of calf }\end{array}$} \\
\hline & Rt & $\mathrm{Lt}$ & Rt & $\mathrm{Lt}$ & Rt & $\mathrm{Lt}$ & Rt & $\mathrm{Lt}$ \\
\hline \multirow{2}{*}{$\begin{array}{l}\text { Inflammation } \\
\text { Erythema, cellulitis, venous } \\
\text { eczema, dermatitis }\end{array}$} & \multicolumn{2}{|c|}{ None } & \multicolumn{2}{|c|}{ Perimalleolar } & \multicolumn{2}{|c|}{$\begin{array}{l}\text { Lower third of } \\
\text { calf }\end{array}$} & \multicolumn{2}{|c|}{$\begin{array}{l}\text { Above lower } \\
\text { third of calf }\end{array}$} \\
\hline & Rt & $\mathrm{Lt}$ & Rt & $\mathrm{Lt}$ & Rt & $\mathrm{Lt}$ & Rt & Lt \\
\hline \multirow{2}{*}{$\begin{array}{l}\text { Induration } \\
\text { Chronic edema, atrophie blanche, } \\
\text { lipodermatosclerosis }\end{array}$} & \multicolumn{2}{|c|}{ None } & \multicolumn{2}{|c|}{ Perimalleolar } & \multicolumn{2}{|c|}{$\begin{array}{l}\text { Lower third of } \\
\text { calf }\end{array}$} & \multicolumn{2}{|c|}{$\begin{array}{l}\text { Above lower } \\
\text { third of calf }\end{array}$} \\
\hline & Rt & $\mathrm{Lt}$ & Rt & $\mathrm{Lt}$ & Rt & $\mathrm{Lt}$ & Rt & $\mathrm{Lt}$ \\
\hline Number of active ulcers & No & & 1 & & 2 & & $\geq 3$ & \\
\hline & Rt & $\mathrm{Lt}$ & Rt & $\mathrm{Lt}$ & Rt & $\mathrm{Lt}$ & Rt & $\mathrm{Lt}$ \\
\hline Active ulcer duration (longest active) & No & & $<3$ & & $>3$ & & $>1$ & \\
\hline & Rt & $\mathrm{Lt}$ & Rt & $\mathrm{Lt}$ & Rt & $\mathrm{Lt}$ & Rt & $\mathrm{Lt}$ \\
\hline Active ulcer size & No & & $<2$ & & $2-6$ & & $>6$ & \\
\hline & Rt & $\mathrm{Lt}$ & Rt & $\mathrm{Lt}$ & Rt & Lt & Rt & $\mathrm{Lt}$ \\
\hline Compression therapy & No & & Int & & Mo & & Dai & \\
\hline & Rt & $\mathrm{Lt}$ & Rt & $\mathrm{Lt}$ & Rt & $\mathrm{Lt}$ & Rt & Lt \\
\hline
\end{tabular}

VCSS - RIGHT: VCSS - LEFT:

Abbreviations: Lt, left; Rt, right.

Source: Adapted with permission from the American Venous Forum Ad Hoc Outcomes Working Group. ${ }^{7}$

standard for clinical reporting of chronic venous disorders. ${ }^{8}$ The most recent revision in 2020 made clinically practical adjustments, noted in - Table 2 . While the clinical (C) classification is most commonly used, all four components (CEAP) are required to make a complete assessment of each limb. The CEAP reporting should always include the date and level of evaluation: Level 1 is based on clinical history and physical exam, Level 2 is noted following formal noninvasive duplex ultrasound imaging, and Level 3 is reserved for documentation after invasive diagnostic or therapeutic procedures.

The clinical (C) classification is descriptive, but also aims to assess clinical change over time. There is now a new subscript for recurrent ( $r$ ) disease for varicose veins and ulcers. Each clinical class is identified as symptomatic (s) or asymptomatic (a). The clinical (C) class characterizes telan- giectasias $(<1 \mathrm{~mm})$ and reticular veins $(<3 \mathrm{~mm})$ as $\mathrm{C} 1$, separate from varicose veins ( $3 \mathrm{~mm}$ or more), which is classified as C2 (-Fig. 1). Edema is C3 class, and characteristically begins in the perimalleolar region, but ascends higher with accumulation of fluid. If asymmetric and increased edema is noted in the left leg, further imaging studies can be performed with cross-sectional venous phase imaging, angiography, or intravascular ultrasound to evaluate for May-Thurner syndrome. Changes in skin and subcutaneous tissue are seen in C4 class, which underwent reorganization in the most recent classification. Eczema and brown pigmentation are classified as C4a. Lipodermatosclerosis, which is fibrosis in the dermis and subcutaneous tissue (-Fig. 2 ), and atrophie blanche, which is a white atrophic scar, both comprise class $4 \mathrm{~b}$. Blue reticular veins and telengiectasias known as corona phlebectatica were newly added as a third 
Table 2 The 2020 update to the CEAP classification, adapted with permission from CEAP classification system and reporting standard, revision 2020

\begin{tabular}{|c|c|}
\hline \multicolumn{2}{|c|}{ CEAP 2020} \\
\hline \multicolumn{2}{|c|}{ Clinical classification (C) } \\
\hline $\mathrm{C}_{0}$ & No visible or palpable signs of venous disease \\
\hline$C_{1}$ & Telengiectasias or reticular veins \\
\hline $\mathrm{C}_{2}$ & Varicose veins \\
\hline$C_{2 r}$ & Recurrent varicose veins \\
\hline$C_{3}$ & Edema \\
\hline $\mathrm{C}_{4}$ & Changes in skin and subcutaneous tissue \\
\hline $\mathrm{C}_{4 a}$ & Pigmentation or eczema \\
\hline $\mathrm{C}_{4 \mathrm{~b}}$ & Lipodermatosclerosis or atrophie blanche \\
\hline $\mathrm{C}_{4 \mathrm{c}}$ & Corona phlebectatica \\
\hline$C_{5}$ & Healed \\
\hline $\mathrm{C}_{6}$ & Active venous ulcer \\
\hline$C_{6 r}$ & Recurrent active venous ulcer \\
\hline \multicolumn{2}{|c|}{ Etiologic classification (E) } \\
\hline$E_{p}$ & Primary \\
\hline $\mathrm{E}_{\mathrm{s}}$ & Secondary \\
\hline $\mathrm{E}_{\mathrm{si}}$ & Secondary-intravenous \\
\hline $\mathrm{E}_{\mathrm{se}}$ & Secondary-extravenous \\
\hline$E_{c}$ & Congenital \\
\hline$E_{n}$ & No cause identified \\
\hline \multicolumn{2}{|c|}{ Anatomic classification (A) } \\
\hline$A_{s}$ & Superficial \\
\hline$A_{d}$ & Deep \\
\hline$A_{p}$ & Perforator \\
\hline$A_{n}$ & No venous anatomic location identified \\
\hline \multicolumn{2}{|c|}{ Pathophysiologic classification (P) } \\
\hline $\mathrm{P}_{\mathrm{r}}$ & Reflux \\
\hline $\mathrm{P}_{\mathrm{o}}$ & Obstruction \\
\hline $\mathrm{P}_{\text {ro }}$ & Reflux and obstruction \\
\hline$P_{n}$ & No pathology identified \\
\hline
\end{tabular}

Source: Lurie et al. ${ }^{8}$

subset, class $4 \mathrm{c}$, and is an indicator for reflux and a risk factor of venous ulceration (- Fig. 3). ${ }^{8}$ Healed ulceration is class C5. The most severe complication is active ulcerations, $\mathrm{C} 6$, which occurs most often at the medial supramalleolar area, at the site of greatest hydrostatic pressure (-Fig. 4). ${ }^{1}$

The etiology $(E)$ characterizes disease into primary $\left(E_{p}\right)$ venous insufficiency or secondary $\left(E_{s}\right)$ to an acquired condition, with new subdivision into intravenous $\left(E_{s i}\right)$, such as deep vein thrombosis, or extravenous $\left(E_{\text {se }}\right)$, such as tumor mass compression. It also characterizes diseases as congenital $\left(E_{c}\right)$ or no cause identified $\left(E_{n}\right)$. For instance, KlippelTrenaunay syndrome (KTS) is a congenital vascular disorder $\left(E_{c}\right)$ characterized by port wine stains, varicose veins, and

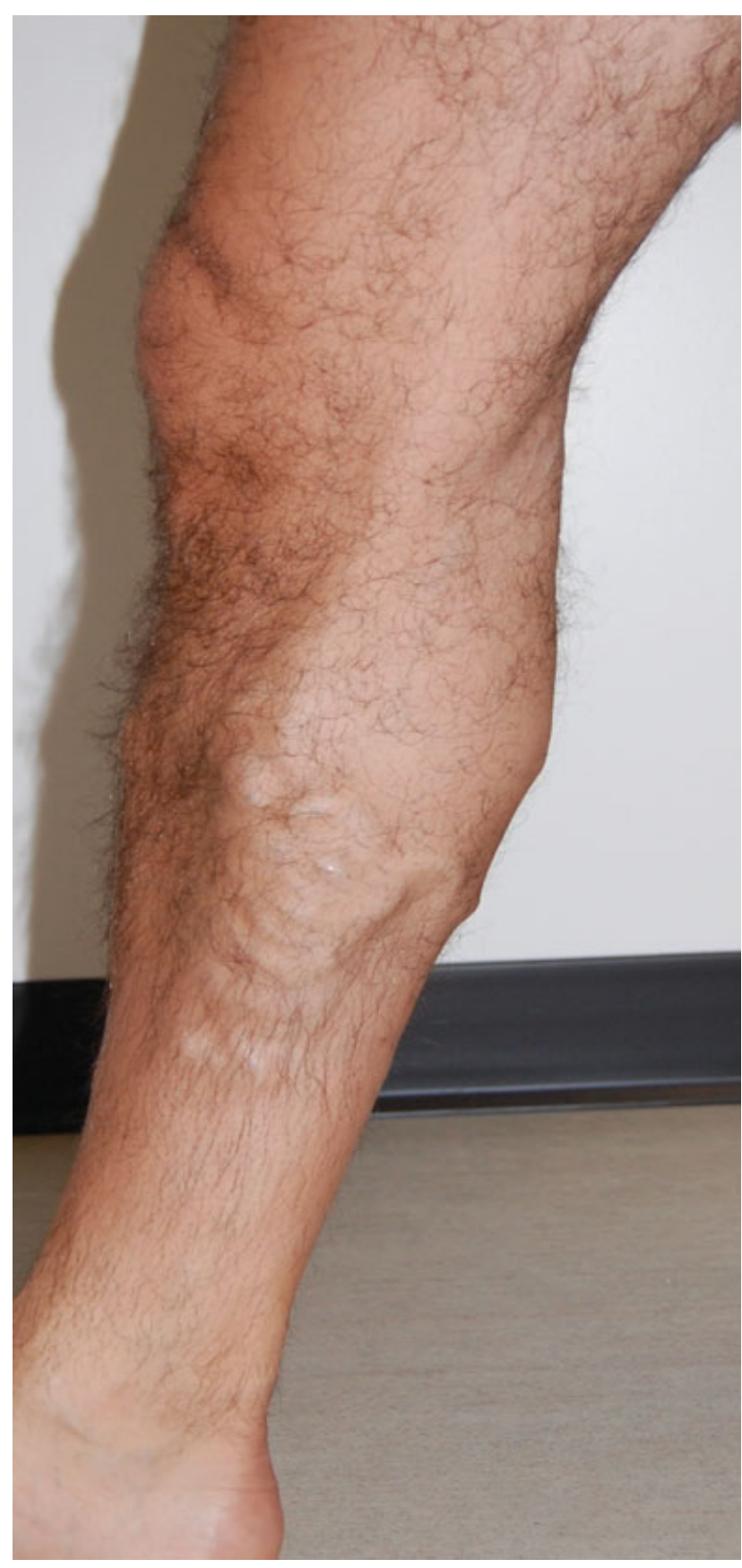

Fig. 1 A network of superficial varicose veins in the medial calf communicating with a dilated and refluxing great saphenous vein (C2).

bony and soft-tissue overgrowth (-Fig. 5). A new diagnosis of KTS or KTS variant can be made at the time of consultation for superficial venous disease by evaluating for skin, soft tissue, or bony changes. ${ }^{9}$

The anatomic (A) classification determines whether diseased segments are in the superficial $\left(A_{s}\right)$, deep $\left(A_{d}\right)$, or perforating $\left(A_{p}\right)$ systems, and can include more than one of the above. In its most detailed form, the CEAP system recognizes 25 venous segments that are now formally described with abbreviations ( - Table 3). Finally, each segment is characterized according to the pathophysiologic $(\mathrm{P})$ classification for underlying mechanism of disease: reflux $\left(\mathrm{P}_{\mathrm{r}}\right)$, 


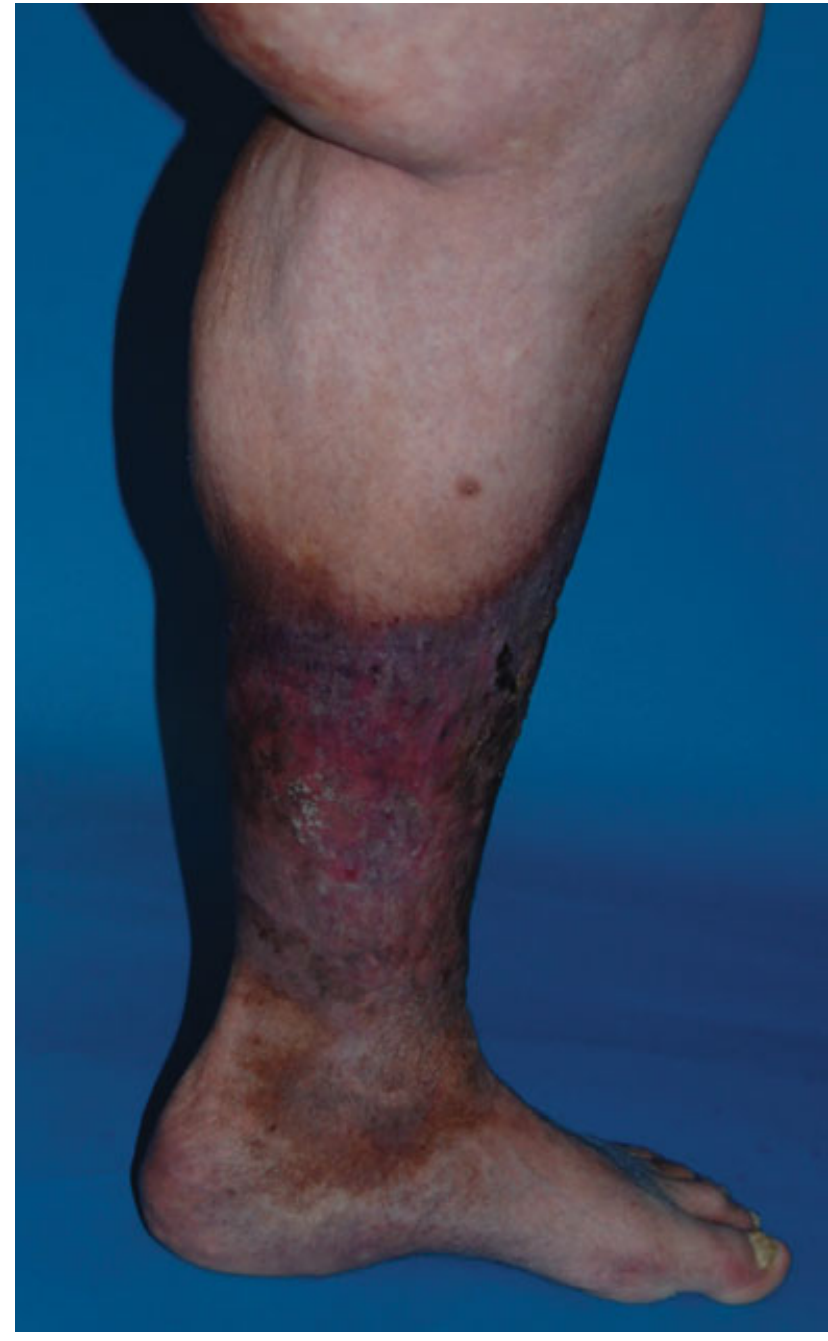

Fig. 2 Lipodermatosclerosis is a chronic inflammatory condition consistent with fibrosis in subcutaneous tissue and hardening of the dermis, accompanied by skin discoloration secondary to hemosiderin deposition $\left(\mathrm{C}_{\mathrm{b}}\right)$.

obstruction $\left(\mathrm{P}_{\mathrm{o}}\right)$, both $\left(\mathrm{P}_{\mathrm{ro}}\right)$ or unidentified $\left(\mathrm{P}_{\mathrm{n}}\right)$. Non-CEAP findings include, for example, ambulatory status, nail and hair changes, and areas of thrombophlebitis and vasculitis.

\section{Ultrasound Evaluation}

Ultrasound evaluation is the gold standard for superficial venous assessment. Both gray scale imaging with a 7.5- to $12-\mathrm{MHz}$ probe and pulsed-wave Doppler imaging are needed. A dedicated ultrasound technologist performs a physical examination with the room lights on to look for cutaneous manifestations of the venous abnormalities. A thorough and detail-oriented ultrasound examination is then completed with emphasis on both anatomy and pathology. Ideally, the patient is upright; however, slight reverse Trendelenburg may be necessary for patient comfort and ergonomic considerations. False-positive and false-negative findings can occur if the patient is not standing; thus, if reflux time falls between 0.5 and 1.1 seconds, an upright examination is essential if possible. ${ }^{10}$ Interrogation for the origin of venous abnormalities such as varicosities and ulceration, and other

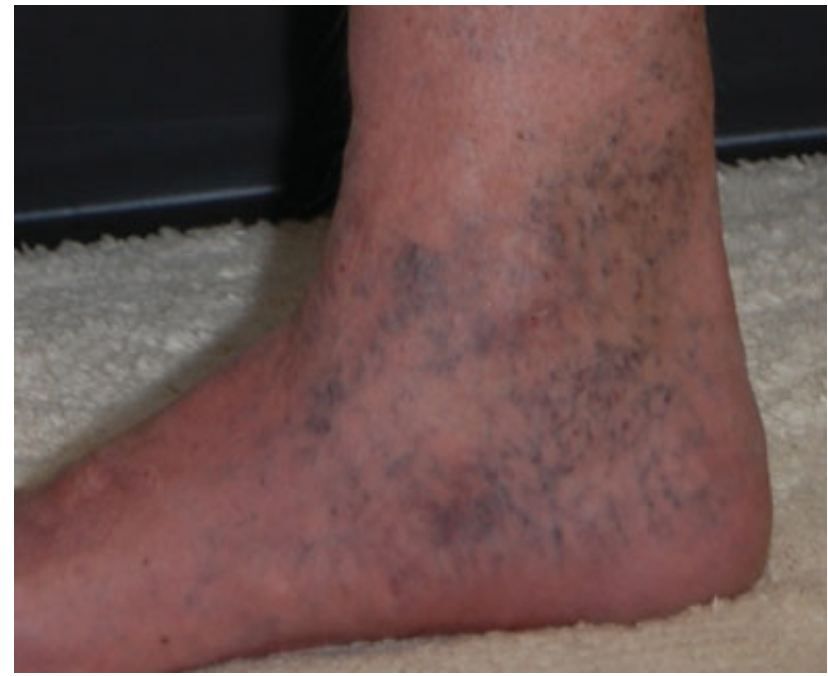

Fig. 3 Corona phlebectatica, or blue telangiectatic and reticular veins around the medial malleolus, is a primary indicator of reflux in the great saphenous vein, or less commonly the small saphenous vein. It is newly added to the CEAP 2020 classification (C4 $4_{c}$.

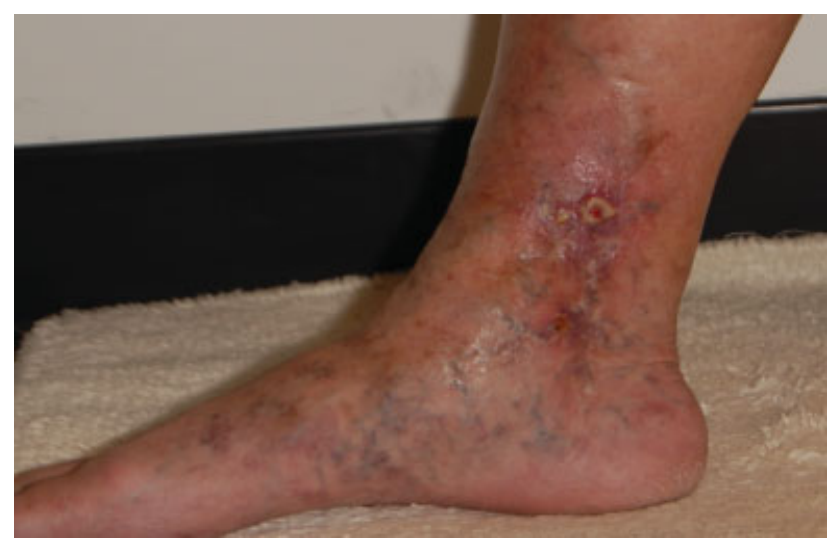

Fig. 4 Multifocal venous ulcerations in the medial malleolus with fibrinous exudate. Also noted inferiorly is white irregular fibrosis and scarring, atrophie blanche, with scattered areas of brown staining and corona phlebectatica $\left(\mathrm{C}_{\mathrm{bc}} 6\right)$.

findings such as edema, calcifications, and Baker's cysts are reported as well.

Standardized lower extremity venous anatomy nomenclature established in an interdisciplinary consensus statement in 2002, updated in 2005, has become the de facto terminology used today. ${ }^{11,12}$ The essential vessels noted on each ultrasound exam are listed in $\mathbf{- T a b l e ~} \mathbf{4}$, and data include reflux time and diameter. Unlike the deep venous system that is named according to the associated artery, the superficial venous system contains more variable anatomy. The two most common superficial branches are the great saphenous vein (GSV) and small saphenous vein (SSV). Both lie between the superficial saphenous fascia and deep muscular fascia, which define the saphenous compartment. ${ }^{13}$ The majority of superficial veins are named by their relationship to the saphenous compartment. ${ }^{12}$

When present, the accessory saphenous veins lie in the saphenous compartment initially and are named for their 


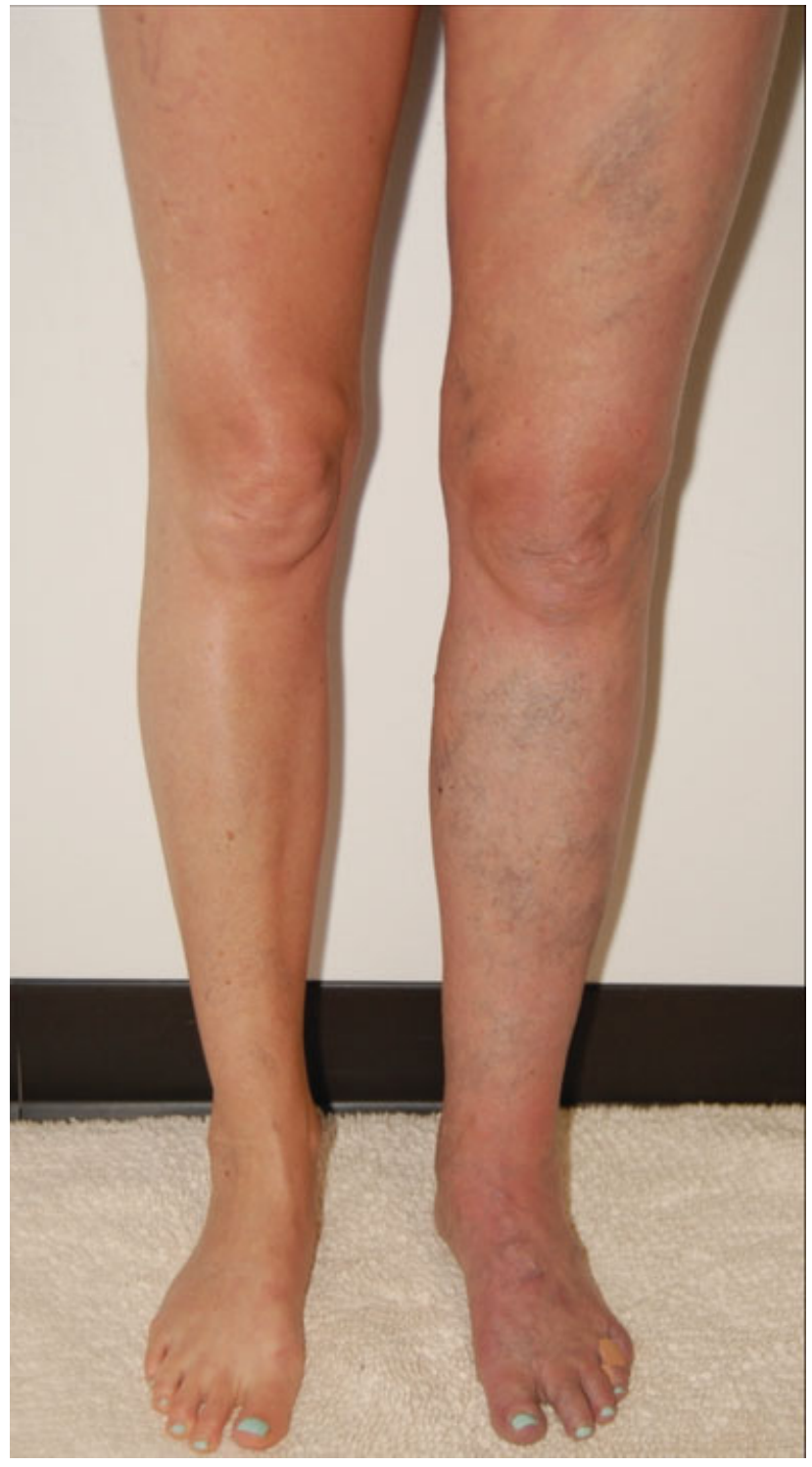

Fig. 5 Extensive port wine staining throughout the left leg, most conspicuous at the medial thigh. Note the increased size of the left leg, with bony and muscular overgrowth throughout. There are varicosities, reticular veins, and telangiectasias present $\left(C 1234_{a} E_{c}\right)$.

relationship to the GSV. The anterior accessory great saphenous vein is found in $14 \%$ of individuals with varicose veins and usually lies anterior and lateral to the GSV. ${ }^{13}$ In distinction, the posterior accessory great saphenous vein is less often seen, and courses medial and posterior to the GSV. The duplicate GSV is similar in size to the GSV, is located within the saphenous compartment, and is infrequently seen with $2 \%$ occurrence. ${ }^{14}$ By contrast, the anterior and posterior thigh circumflex branches of the GSV lie superficial to the saphenous compartment.

In 30\% of cases, the GSV may have a segmental hypoplastic or aplastic segment of variable length, particularly if there is a large subcutaneous tributary. ${ }^{13}$ Studies have shown that the incidence of hypoplasia is higher in those with saphenofemoral junction (SFJ) incompetence or varices. ${ }^{15}$ The segmental aplasia/hypoplasia continuum classifies the GSV into four types: (1) single GSV, (2) segmental aplasia, (3) segmen-
Table 3 CEAP anatomic classification, adapted with permission from CEAP classification system and reporting standard, revision 2020

\begin{tabular}{|c|c|c|c|}
\hline \multicolumn{4}{|c|}{ CEAP 2020} \\
\hline \multicolumn{4}{|c|}{ Anatomic classification (A) } \\
\hline \multirow[t]{8}{*}{$A_{s}$} & Superficial & & \\
\hline & & Tel & Telangiectasia \\
\hline & & Ret & Reticular veins \\
\hline & & GSVa & $\begin{array}{l}\text { Great saphenous vein } \\
\text { above knee }\end{array}$ \\
\hline & & GSVb & $\begin{array}{l}\text { Great saphenous vein } \\
\text { below knee }\end{array}$ \\
\hline & & SSV & Small saphenous vein \\
\hline & & AASV & $\begin{array}{l}\text { Anterior accessory } \\
\text { saphenous vein }\end{array}$ \\
\hline & & NSV & Nonsaphenous vein \\
\hline \multirow[t]{18}{*}{$A_{d}$} & Deep & & \\
\hline & & IVC & Inferior vena cava \\
\hline & & Ret & Reticular veins \\
\hline & & CIV & Common iliac vein \\
\hline & & IIV & Internal iliac vein \\
\hline & & EIV & External iliac vein \\
\hline & & PELV & Pelvic veins \\
\hline & & CFV & Common femoral vein \\
\hline & & DFV & Deep femoral vein \\
\hline & & FV & Femoral vein \\
\hline & & POPV & Popliteal vein \\
\hline & & TIBV & Crural (tibial) vein \\
\hline & & PRV & Peroneal vein \\
\hline & & ATV & Anterior tibial vein \\
\hline & & PTV & Posterior tibial vein \\
\hline & & MUSV & Muscular veins \\
\hline & & GAV & Gastrocnemius vein \\
\hline & & SOV & Soleal vein \\
\hline \multirow[t]{3}{*}{$A_{p}$} & Perforator & & \\
\hline & & TPV & Thigh perforator vein \\
\hline & & CPV & Calf perforator vein \\
\hline$A_{n}$ & $\begin{array}{l}\text { No venous } \\
\text { anatomic } \\
\text { location } \\
\text { identified }\end{array}$ & & \\
\hline
\end{tabular}

Source: Lurie et al. ${ }^{8}$

tal hypoplasia, and (4) saphenous bow variation. Bow variation is further subdivided into three types based on take-off and reentry in the calf, thigh, or mid-leg. Insufficient segments can occur in the intracompartmental vein, extracompartmental vein, or both. ${ }^{16}$

The saphenous nerve lies in the saphenous compartment. It is the longest sensory branch of the femoral nerve and 
Table 4 Superficial venous insufficiency evaluation requires assessment of the following vessels in each leg, with specific annotation for reflux or no reflux, reflux time in seconds, and diameter in centimeters

\begin{tabular}{|l|l|}
\hline Abbreviation & Full terminology \\
\hline GSV & Great saphenous vein \\
\hline SFJ & Saphenofemoral junction \\
\hline S THI & Superior thigh \\
\hline M THI & Medial thigh \\
\hline I THI & Inferior thigh \\
\hline KNEE & KNEE \\
\hline S CALF & Superior calf \\
\hline M CALF & Medial calf \\
\hline I CALF & Inferior calf \\
\hline AAGSV & Anterior accessory great saphenous vein \\
\hline PAGSV & Posterior accessory great saphenous vein \\
\hline SAGSV & Superficial accessory great saphenous \\
\hline vein \\
\hline DUP & Duplicate great saphenous vein \\
\hline Post thigh & Posterior thigh circumflex \\
\hline Ant thigh & Anterior thigh circumflex \\
\hline SSV & Small saphenous vein \\
\hline SPJ & Sapheno-popliteal junction \\
\hline S CALF & Superior calf \\
\hline M CALF & Medial calf \\
\hline I CALF & Inferior calf \\
\hline V Giac & Vein of giacomini \\
\hline Deep thigh & Deep thigh extension \\
\hline PERF & Perforators \\
\hline 1 & \\
\hline 2 & Varicose veins \\
\hline 3 & \\
\hline Varicose veins & \\
\hline 1 & \\
\hline 2 & \\
\hline & \\
\hline & \\
\hline & \\
\hline
\end{tabular}

provides sensory supply to the medial knee, leg, and foot. Inferior to the adductor canal, in the calf, the GSV and nerve become more intimately associated. ${ }^{17}$

The SFJ, with its terminal and preterminal valves, is crucial for satisfactory hemodynamics and prevention of reflux from the common femoral vein. The location, valve competency, and diameter of the SFJ are documented (-Fig. 6). The inferior epigastric vein inflow from the pelvis occurs just below the SFJ, and documentation of this drainage is crucial, particularly prior to intervention, as this inflow provides

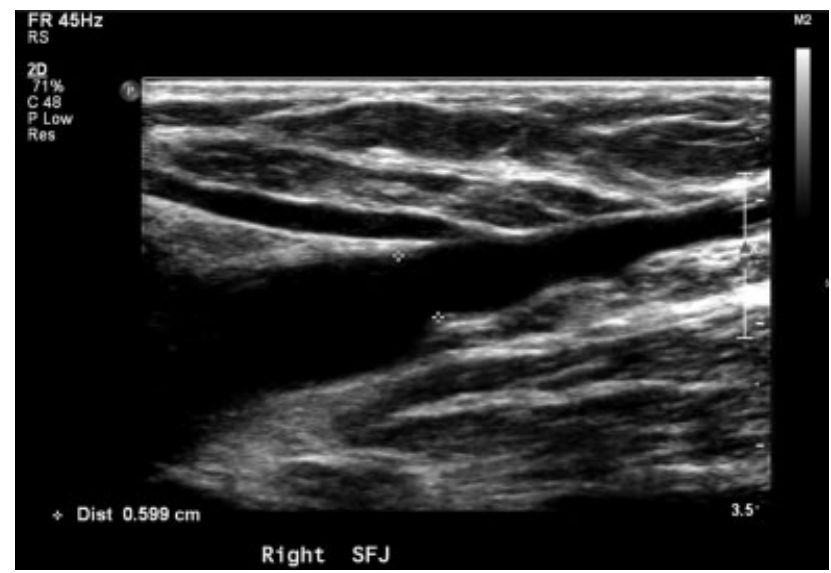

Fig. 6 Saphenofemoral junction measurement is in the longitudinal projection at the junction, which is superior to the inferior epigastric inflow.

patency at the SFJ. ${ }^{18}$ Additional drainage from the external pudendal and external circumflex iliac veins occurs in this region as well. ${ }^{4}$

Like the SFJ, the sapheno-popliteal junction (SPJ) has a terminal valve and preterminal valve. The SSV may terminate in the popliteal vein, or extend as a superficial or deep thigh extension. When the SSV continues as a superficial thigh extension, it is known as the vein of Giacomini, which most commonly joins the posterior thigh circumflex vein before entering the GSV, thereby becoming an intersaphenous vein. $^{13}$

The tibial nerve, a motor and sensory nerve, is the largest terminal branch of the sciatic nerve. It is posterior to the popliteal vein and runs lateral to medial near the SPJ. ${ }^{19}$ The sural nerve is a pure sensory nerve that is formed from branches of the tibial nerve. It is located adjacent to the SSV. The sural nerve gets closer to the SSV in the lower two-thirds of the calf, and, when able, is identified so that it can be avoided during treatment. $^{19}$

Perforating veins connect the superficial and deep systems and are classified by their circumferential location (medial, lateral, posterior, or anterior) as well as their superior to inferior location (gluteal, thigh, knee, leg, ankle, or foot). ${ }^{20}$ Tributary veins, by contrast, connect superficial to superficial veins, and their location is seen on an ultrasound (-Fig. 7). Tributary veins can be large and may be the dominant drainage of the leg. ${ }^{13}$ Varicose veins are tributary veins.

Before evaluating the pathology in the superficial system, the deep system is always initially interrogated for potential obstruction and reflux. The superficial system is then studied in its entirety for abnormal reflux, thrombosis, and vein size, which can be documented on an ultrasound (-Fig. 7). Reflux is measured on pulse-wave Doppler ultrasound as seconds of reversed flow (above baseline) after augmentation. Reflux is abnormal if it is greater than 0.5 seconds for superficial and perforator veins, or 1 second for deep veins. ${ }^{21}$ The exact time of reflux at each segment is recorded. Reflux is evaluated with calf augmentation below the vessel being imaged. Machine augmentation is an alternative to manual 

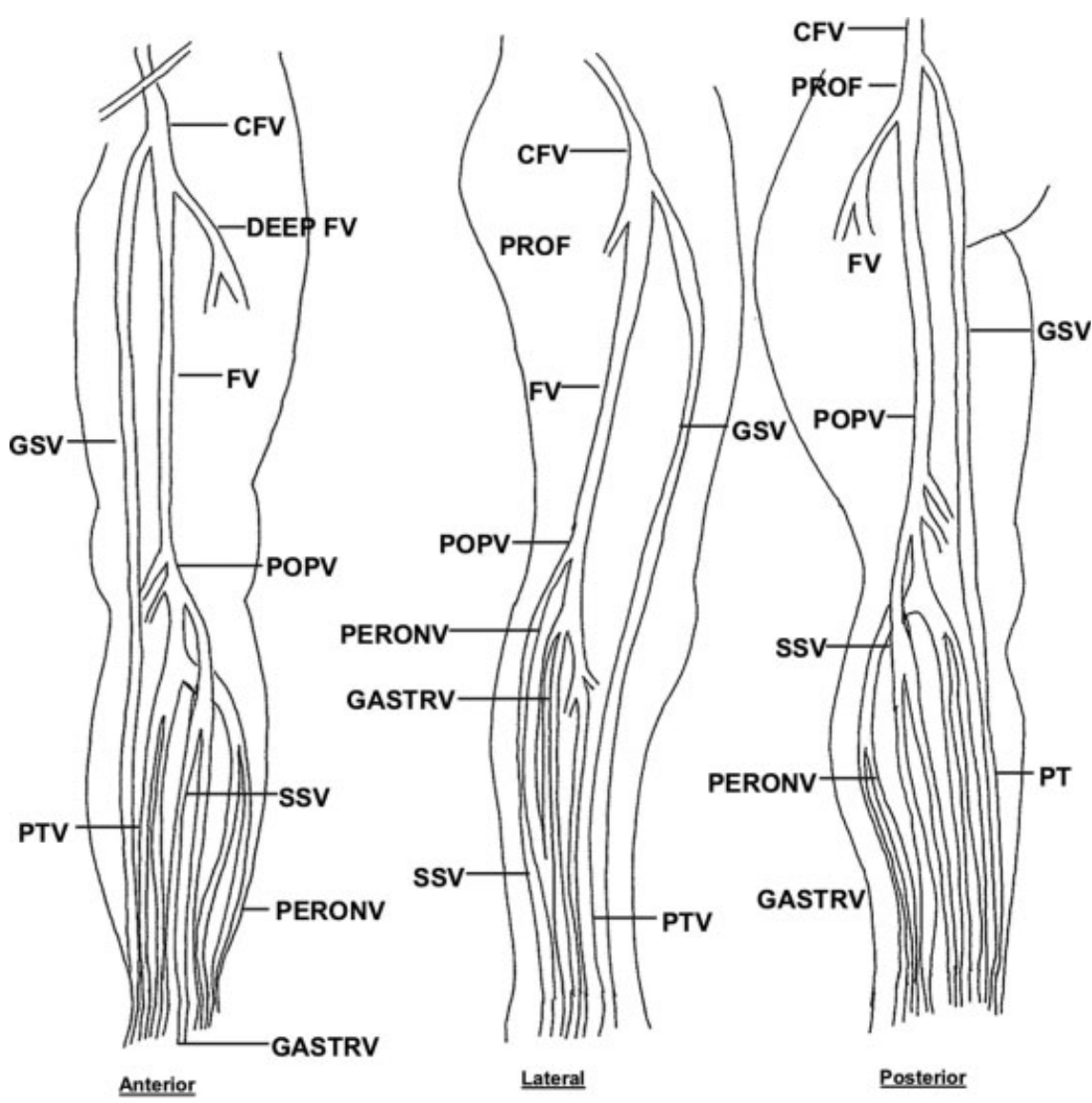

Fig. 7 Template anatomy drawing of the deep and superficial venous systems used to annotate ultrasound findings including segmental areas of venous reflux. CFV, common femoral vein; DEEP FV, deep femoral vein; GASTRV, gastrocnemius vein; GSV, great saphenous vein; PERONV, peroneal vein; POPV, popliteal vein; PROF, deep femoral vein (formerly known as Profunda femoris vein); PT, posterior tibial; PTV, posterior tibial vein; SSV, small saphenous vein.

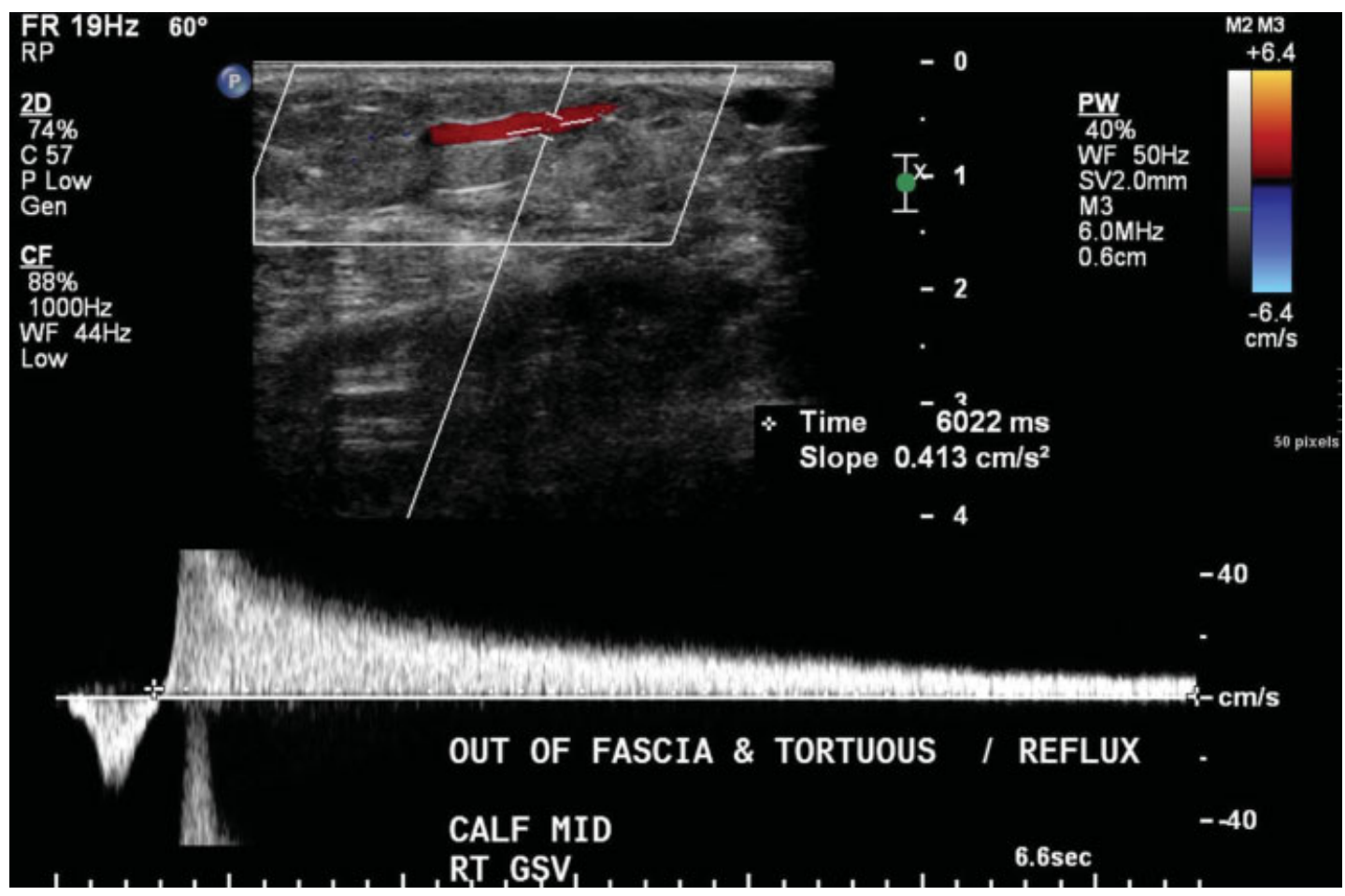

Fig. 8 Venous reflux of 6 seconds in the great saphenous vein after manual calf augmentation, measured with cursor box in the direction of the blood flow, parallel to the vessel wall. The scale is adjusted according to the amplitude of flow. 


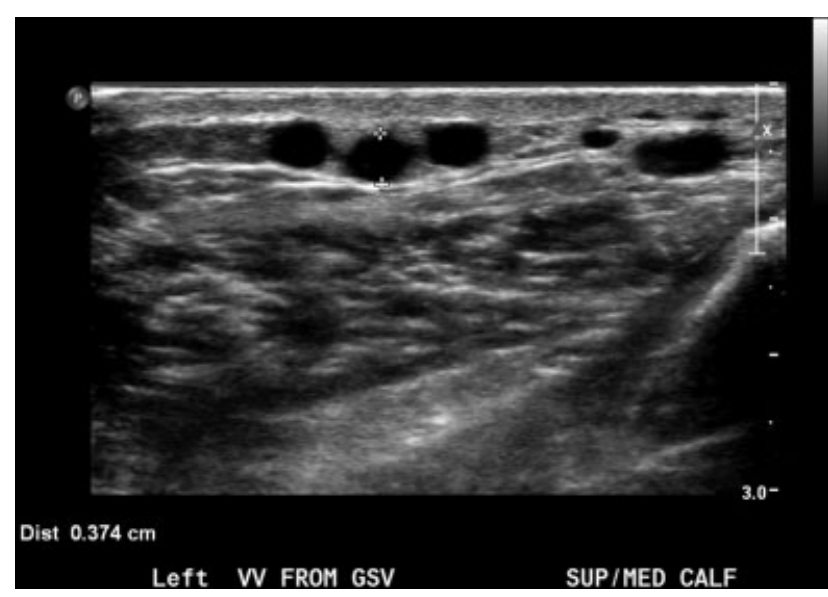

Fig. 9 Varicose vein on gray-scale ultrasound measured anterior to posterior in transverse projection, with cursor right on the vein wall.

compression that can give steady constant pressure and release. Valsalva is acceptable to evaluate for obstruction and reflux at the common femoral vein and the SFJ, but not below these levels. Proper waveform and directionality must be demonstrated on Doppler ultrasound with a flow pattern of reflux above the baseline (-Fig. 8). Additional findings may include lack of valve closure, venous blood stasis, and Rouleau phenomenon.
Vein diameter is properly measured in transverse projection, from anterior to posterior, with grey scale ultrasound (-Fig. 9). Cursors are accurately placed on the vein wall. Measurements are neither obtained at branch points nor with color Doppler because of blooming. Perforator vein diameter is measured as it traverses the deep fascia (-Fig. 10). If the diameter for perforator veins is more than $3.5 \mathrm{~mm}$, reflux is typically present. ${ }^{22}$ Calcification of the vein wall, when seen, is also a sign of venous pathology.

\section{Conclusion}

A thorough history, including documentation of a VCSS-R; a complete physical exam with an up-to-date CEAP score; and a properly performed ultrasound exam are essential for a comprehensive venous evaluation. Each limb is evaluated and recorded separately. Duplex ultrasonography by a dedicated technologist is required not only for a thorough baseline evaluation but also to monitor response after therapy. Whether treating with conservative measures or planning for intervention, a systematic and standardized assessment is imperative.

\section{Disclosures}

J.M.M. receives grant funding from Angiodynamics Inc.; is advisory board member of Argon Medical Inc. and Boston Scientific Inc.; and is consultant for BD Bard, Inari Medical, Penumbra Medical Inc., Thrombolex Inc., and Pavmed Inc.

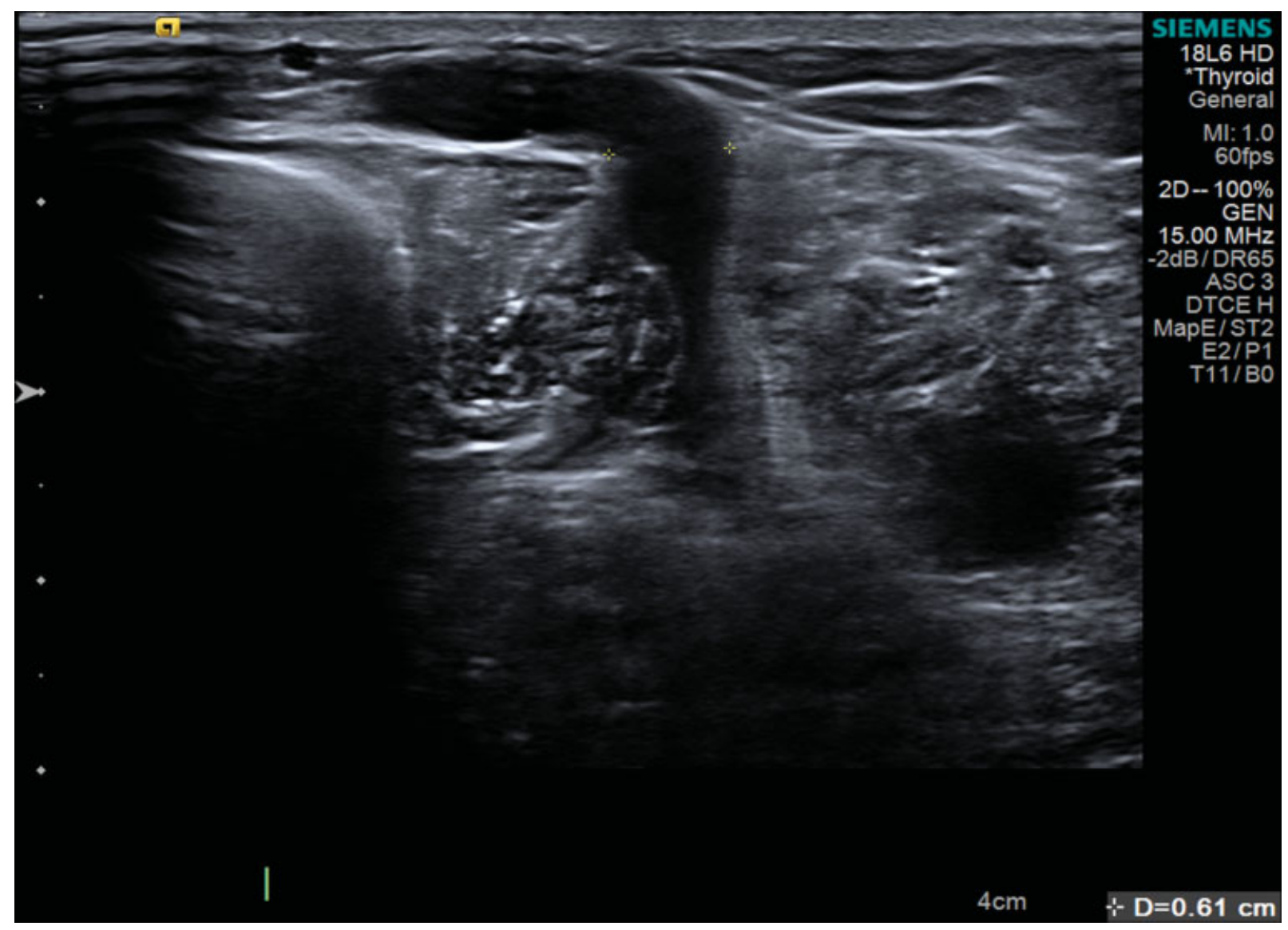

Fig. 10 Perforator veins are measured as they extend from the superficial into the deep system at the fascia and in perpendicular axis so that it is a true diameter, not in oblique. 


\section{Conflict of Interest \\ None declared.}

\section{Acknowledgments}

Special thanks to the UCLA Ultrasound sonographers for their dedication, hard work, and help in the preparation of this manuscript.

\section{References}

1 Eberhardt RT, Raffetto JD. Chronic venous insufficiency. Circulation 2014;130(04):333-346

2 McLafferty RB, Lohr JM, Caprini JA, et al. Results of the national pilot screening program for venous disease by the American Venous Forum. J Vasc Surg 2007;45(01):142-148

3 Fan CM. Venous pathophysiology. Semin Intervent Radiol 2005; 22(03):157-161

4 Baliyan V, Tajmir S, Hedgire SS, Ganguli S, Prabhakar AM. Lower extremity venous reflux. Cardiovasc Diagn Ther 2016;6(06):533-543

5 Bergan JJ, Schmid-Schönbein GW, Smith PD, Nicolaides AN, Boisseau MR, Eklof B. Chronic venous disease. N Engl J Med 2006;355(05):488-498

6 Wells QS. Varicose veins reach new heights. Circulation 2018;138 (25):2881-2883

7 Vasquez MA, Rabe E, McLafferty RB, et al; American Venous Forum Ad Hoc Outcomes Working Group. Revision of the venous clinical severity score: venous outcomes consensus statement: special communication of the American Venous Forum Ad Hoc Outcomes Working Group. J Vasc Surg 2010;52(05):1387-1396

8 Lurie F, Passman M, Meisner M, et al. CEAP classification system and reporting standard, revision 2020. J Vasc Surg Venous Lymphat Disord 2020;8(03):342-352

9 Alwalid O, Makamure J, Cheng QG, et al. Radiological aspect of Klippel-Trénaunay syndrome: a case series with review of literature. Curr Med Sci 2018;38(05):925-931

10 Zygmunt JA. Duplex ultrasound for chronic venous insufficiency. J Invasive Cardiol 2014;26(11):E149-E155

11 Caggiati A, Bergan JJ, Gloviczki P, Jantet G, Wendell-Smith CP, Partsch HInternational Interdisciplinary Consensus Committee on Venous Anatomical Terminology. Nomenclature of the veins of the lower limbs: an international interdisciplinary consensus statement. J Vasc Surg 2002;36(02):416-422

12 Caggiati A, Bergan JJ, Gloviczki P, Eklof B, Allegra C, Partsch HInternational Interdisciplinary Consensus Committee on Venous Anatomical Terminology. Nomenclature of the veins of the lower limb: extensions, refinements, and clinical application. J Vasc Surg 2005;41(04):719-724

13 Oğuzkurt L. Ultrasonographic anatomy of the lower extremity superficial veins. Diagn Interv Radiol 2012;18(04):423-430

14 Kockaert M, de Roos KP, van Dijk L, Nijsten T, Neumann M. Duplication of the great saphenous vein: a definition problem and implications for therapy. Dermatol Surg 2012;38(01):77-82

15 Caggiati A, Mendoza E. Segmental hypoplasia of the great saphenous vein and varicose disease. Eur J Vasc Endovasc Surg 2004;28 (03):257-261

16 Deniz S, Tureli D, Akpinar B, Oguzkurt L. A potential therapeutic pitfall in the treatment of venous reflux due to variant planar anatomy of varicose segments. Phlebology 2018;33(07):470-474

17 Ghosh A, Chaudhury S. Morphology of saphenous nerve in cadavers: a guide to saphenous block and surgical interventions. Anat Cell Biol 2019;52(03):262-268

18 Cestaro G, Furino E, Solimeno G, et al. The role of superficial epigastric vein sparing in the treatment of chronic venous disease: a retrospective study. Acta Phlebol 2015;15(03):143-147

19 Kerver ALA, van der Ham AC, Theeuwes HP, et al. The surgical anatomy of the small saphenous vein and adjacent nerves in relation to endovenous thermal ablation. J Vasc Surg 2012;56(01): 181-188

20 Meissner MH. Lower extremity venous anatomy. Semin Intervent Radiol 2005;22(03):147-156

21 Kuyumcu G, Salazar GM, Prabhakar AM, Ganguli S. Minimally invasive treatments for perforator vein insufficiency. Cardiovasc Diagn Ther 2016;6(06):593-598

22 Gloviczki P, Comerota AJ, Dalsing MC, et al. The care of patients with varicose veins and associated chronic venous diseases: clinical practice guidelines of the Society for Vascular Surgery and the American Venous Forum. J Vasc Surg 2011;53(5Suppl):2S-48S 